\title{
Verification of ACI- 549 Code for Flexural Strengthening of Reinforced Concrete Beams Using FRCM
}

\author{
Muhammad Shekaib Afzal \\ shekaib@qu.edu.qa \\ Department of Civil and Architectural Engineering, Qatar University, Doha, Qatar \\ Usama Ebead \\ uebead@qu.edu.qa \\ Department of Civil and Architectural Engineering, Qatar University, Doha, Qatar
}

\begin{abstract}
This paper presents an analytical study to verify the ACI 549-4R-16 code for experimentally tested Reinforced Concrete (RC) beams, which were strengthened to enhance the flexural capacity using Fiber-Reinforced Cementitious Mortars (FRCM). Twelve RC beam specimens having $2500 \mathrm{~mm}$ length, $150 \mathrm{~mm}$ width, and $260 \mathrm{~mm}$ depth were prepared with two different reinforcement ratios $\left(\rho_{-} s^{\wedge} \mathrm{D} 12=0.72 \%\right.$ and $\rho_{-}$ $\mathrm{s}^{\wedge} \mathrm{D} 16=1.27 \%$ ), and were then strengthened with two different FRCM systems, namely carbon and polyparaphenylene-benzobisoxazole (PBO) FRCM systems. Two RC beams were tested as control specimens. Six beams were externally reinforced using single, double and triple layers of carbon FRCM system, while the remaining four beams were repaired with one and two layers of PBO FRCM system. The strengthened RC beams were tested in flexural under four-point monotonic loading. The experimental results revealed that a reasonable gain in flexural strength was achieved for both FRCM systems, with up to $78 \%$ increase in flexural capacity for carbon FRCM systems and up to $27.5 \%$ for PBO FRCM system over that of their control specimens. Further, the results obtained from the theoretical approach using the ACI 549 code conform well with the experimental loadcarrying capacities. Moreover, the values obtained for experimental to theoretical ratio $\left(\frac{P_{V}}{P_{T}}\right)$ are quite close to 1.00 which somewhat shows satisfactory computational results.
\end{abstract}

Keywords: Fabric-reinforced cementitious mortar; Flexural strengthening; Reinforced concrete beams; Reinforcement ratios; FRCM systems

\section{INTRODUCTION}

Recently, several studies on strengthening of Reinforced Concrete (RC) structures have been focused on the application of Fiber Reinforced Polymer (FRP) Externally Bonded (EB) with polymer-based pastes (Abdel Baky et al., 2007; Aidoo et al., 2006; Almassri et al., 2014; Barros \& Fortes, 2005; Capozucca, 2014; Ebead \& Saeed, 2013; Ebead \& Saeed, 2014; Elsayed et al., 2007; Elsayed et al., 2009; Kotynia et al., 2008; Kreit et al., 2010; Neale et al., 2006; Teng et al., 2006; Ebead, 2011). Recently, a new strengthening technique has been introduced, that uses Fabric Reinforced Cementitious Matrix (FRCM) systems for reinforced concrete structures (Arboleda et al., 2015; Babaeidarabad et al., 2014; Loreto et al., 2015; Ombres, 2011; Ombres, 2015; Tetta et al., 2015; Triantafillou \& Papanicolaou, 2006). The existing studies have shown great success of FRCM in improving the performance of repaired RC elements as an external 
strengthening system. This relatively new technique (FRCM strengthening technique) is a viable repair/strengthening solution in the Gulf where extremely elevated heat, severe humidity, and elevated salt amounts round the concrete foundations that can severely deteriorate the concrete and steel reinforcement (Ebead et al., 2016).

This paper presents the analytical method to verify the ACI 549-4R-16 code (ACI 549, 2016) for experimentally tested Reinforced Concrete (RC) beams, which were repaired to enhance their flexural performance using Fiber-Reinforced Cementitious Mortars (FRCM). Twelve RC beams were tested under four-point monotonic loading. The beams were externally reinforced with two different FRCM systems, namely, carbon and polyparaphenylene-benzobisoxazole (PBO) FRCM systems. The test matrix involves two different reinforcement ratios and several combinations of fabric plies. The experimental results were compared with those of the analytical approach (using ACI 549 code).

\section{EXPERIMENTAL INVESTIGATION}

\subsection{Materials}

\subsubsection{Concrete}

Ready mix concrete was used to cast the beam specimens. The design mix proportions per each cubic meter of concrete were $1,100 \mathrm{~kg}$ of gravel, $370 \mathrm{~kg}$ of ordinary Portland cement and $800 \mathrm{~kg}$ of sand. The water-to-cement ratio was kept at 0.45 .

\subsubsection{Reinforcing Steel Rebar's}

Grade B (BS 4449, 2005) steel bars were used as reinforcement for RC beams: 8 $\mathrm{mm}$ diameter bars were used for all the transverse steel reinforcement and also for the compression reinforcement, while 12 and $16 \mathrm{~mm}$ bars were used for the main flexural reinforcement. The yield stress and elastic modulus of these steel rebars are $520 \mathrm{MPa}$ and $200 \mathrm{GPa}$, respectively.

\subsubsection{Textile Reinforced Mortar (FRCM)}

Two commercially available FRCM systems have been utilized in this study. The first system consists of PBO textile with Ruredil X Mortar M750 and the second one includes carbon textile with Sika Mono top-612 Mortar. Table-1 reports the mechanical properties for each textile, provided by the manufacturer.

Table 1: Textile geometric and mechanical properties in warp direction (data adopted from Ruredil, 2016 \& S\&P, 2016)

\begin{tabular}{|l|l|l|l|l|}
\hline Textile Type & $\begin{array}{l}\text { Area per unit width }\left(\boldsymbol{A}_{f}\right), \\
\left(\mathrm{mm}^{2} / \mathrm{mm}\right)\end{array}$ & $\begin{array}{l}\text { Elastic Modulus } \\
(\mathrm{GPa})\end{array}$ & $\begin{array}{l}\text { Tensile strength } \\
(\mathrm{GPa})\end{array}$ & $\begin{array}{l}\text { Ultimate } \\
\text { Strain }(\%)\end{array}$ \\
\hline PBO & 0.05 & 270 & 5.80 & 2.15 \\
\hline Carbon & 0.157 & 240 & 4.30 & 1.75 \\
\hline
\end{tabular}

Further, FRCM test coupons $(410 \times 50 \times 10 \mathrm{~mm})$ were tested after 28 days curing period to obtain the tensile properties for each FRCM composite in accordance with AC434 (ICC, 2013). The tensile characterization test results are presented in Table 2. 
Table 2: FRCM composite tensile characterization properties

\begin{tabular}{|l|l|l|l|}
\hline Textile composite Type & $\begin{array}{l}\text { Elastic modulus of cracked } \\
\text { specimen, }\left(\boldsymbol{E}_{f}\right), \\
(\mathrm{GPa})\end{array}$ & $\begin{array}{l}\text { Ultimate Tensile } \\
\text { strength, } f_{\mathrm{fu}}(\mathrm{GPa})\end{array}$ & $\begin{array}{l}\text { Ultimate } \\
\text { Strain }(\%)\end{array}$ \\
\hline PBO & 121 & 2.59 & 2.30 \\
\hline Carbon & 151 & 2.10 & 1.25 \\
\hline
\end{tabular}

\subsection{Test Specimens}

Twelve (12) beam specimens ( $2500 \mathrm{~mm}$ long, $260 \mathrm{~mm}$ deep and $150 \mathrm{~mm}$ wide) were tested in this research. The parameters investigated were: i) reinforcement ratios $\left(\rho_{\mathrm{s}}^{\text {D12 }}\right.$ $=0.72 \%$ and $\rho_{\mathrm{s}}^{\mathrm{D} 16}=1.27 \%$ ), ii) FRCM strengthening systems, and iii) number of textile/ fabric layers. Out of 12 beam specimens, 2 beams were used as control specimens (not repaired), one each with the main reinforcing bars of $2 \mathrm{D} 12\left(\rho_{\mathrm{s}}^{\mathrm{D} 12}=0.72 \%\right)$ and $2 \mathrm{D} 16$ $\left(\rho_{\mathrm{s}}^{\mathrm{D} 16}=1.27 \%\right)$, respectively. The effective depth of the beam was fixed at $210 \mathrm{~mm}$ for all of the tested specimens. Four beams were repaired with two different PBO-FRCM strengthening schemes (one and two layers of textiles). The remaining six beams were repaired with three different Carbon-FRCM strengthening schemes (one, two and three layers of textiles).

The procedure of FRCM strengthening includes the following steps: first, the soffit of the beam was roughened/sandblasted to a level where the smooth outer layer concrete was removed up to 2-3 $\mathrm{mm}$ depth and some fine aggregates were exposed. Next, the beams were covered with hessian cloth and water was sprinkled over the beam for at least 30 minutes prior to application of FRCM strengthening technique. Figure 1 shows a typical FRCM-repaired beam specimen.
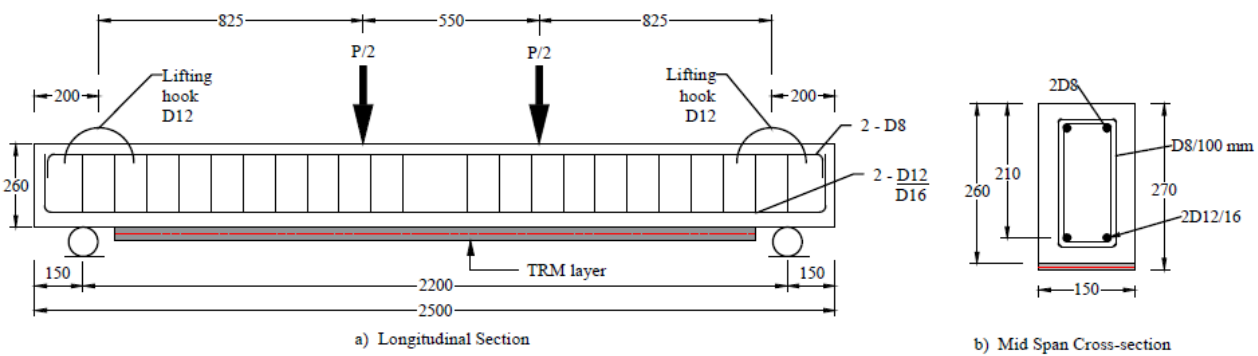

Figure 1:Longitudinal and cross-sectional details oftypical FRCMrepaired beam specimen (All dimensions are in $\mathrm{mm}$ )

Table-3 shows the test matrix, in which each specimen is identified using the "T-R-L" nomenclature, where: " $T$ " denotes the FRCM strengthening scheme (CR for Carbon and PB for PBO); " $R$ " denotes the main reinforcement bar ratio (R12 for $\rho_{\mathrm{s}}{ }^{\mathrm{D} 2}=0.72 \%$ and $\mathrm{R} 16$ for $\rho_{\mathrm{s}}^{\mathrm{D} 16}=1.27 \%$ ); and " $L$ " denotes the number of textile layers ( $\mathrm{L} 1$ for single layer, L2 for two layers, and L3 for three layers).

Further, the amount of FRCM composite layers is expressed in terms of equivalent stiffness for FRCM composite, $\kappa^{\mathrm{t}}$ given by $\kappa^{\mathrm{t}}=n A_{f} E_{f} / b_{s}$, as listed in Column 2 of Table 
3, where $\boldsymbol{A}_{f}$ is the equivalent area of each yarn of textile/fabric per unit width (Table 1), $\boldsymbol{b}_{\mathrm{s}}$ is width of the tensile characterization coupon sample, $\boldsymbol{n}$ is the number of yarns of fabric within the width of the coupon sample, and $\boldsymbol{E}_{f}$ is the cracked elastic modulus of the FRCM composite in $N / \mathrm{mm}^{2}$ (Table 2). This equivalent stiffness parameter is important as the values of $A_{f}, n$, and $E_{f}$ are different for carbon and PBO FRCM systems. The comparison between the two FRCM systems was made based on their equivalent values. For instance, the normalization of to a single layer of carbon FRCM $(\boldsymbol{\kappa}=1422$ MPa) gives following expressions for each FRCM system: $\boldsymbol{\kappa}$ for 1 layer of carbon, $2 \times \boldsymbol{\kappa}$ for 2 layers of carbon, $3 \times \boldsymbol{\kappa}$ for 3 layers of carbon, $0.42 \times \boldsymbol{\kappa}$ for 1 layer of PBO, and $0.85 \times \boldsymbol{\kappa}$ for 2 layers of $\mathrm{PBO}$. These normalized values clearly suggest that the equivalent stiffness of the PBO FRCM is approximately half that of the Carbon FRCM system.

\subsection{Test Setup and Instrumentation}

The test setup for the beam specimens is shown in Figure 2. Displacement control mode with a loading rate of $1 \mathrm{~mm} / \mathrm{min}$ was used for testing the beam specimens. The tested beam was mounted in Instron 1500HDX Static Hydraulic Universal Testing machine as shown in Figure 2.

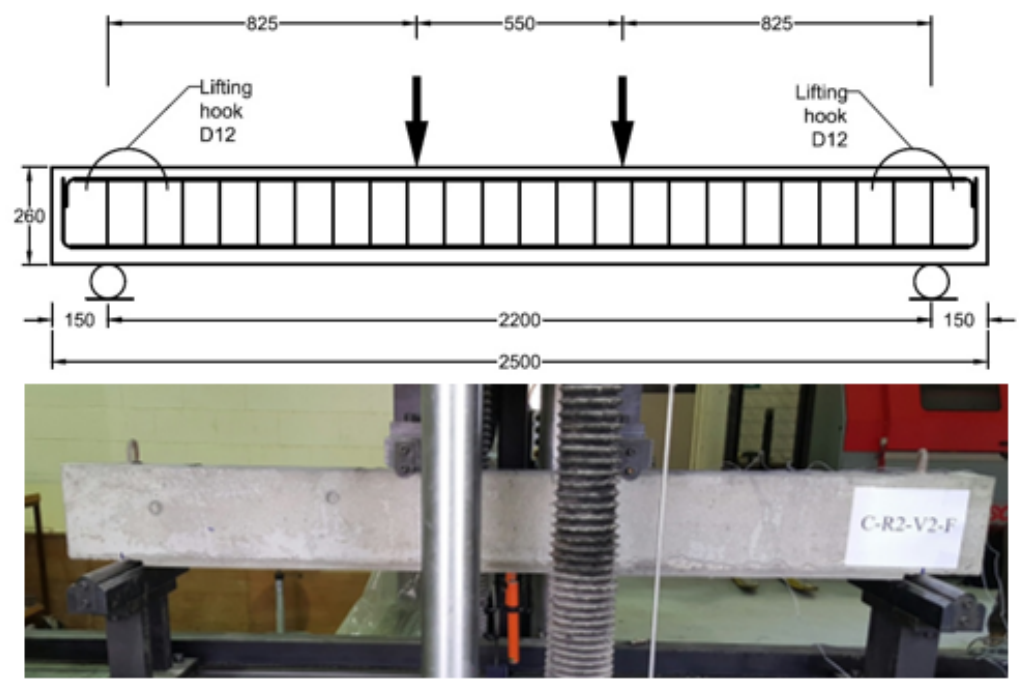

Figure 2: Instron Universal Testing Machine with loading pattern

\section{EXPERIMENTAL FINDINGS}

The test findings include the plots for load versus mid span-deflection, along with maximum load and deformation characteristics. The cracking patterns and failure mode characteristics are also discussed. Table 3 summarizes the experimental results for all tested specimens. Columns 4 and 5 of Table 3 list the maximum capacity $(P \mathbf{u})$ for each beam and the increase in $P \mathbf{u}$ with respect to the corresponding reference specimen. 
Table 3: Test Matrix and summary of Experimental Results (Ebead et al., 2016)

\begin{tabular}{|c|c|c|c|c|c|c|c|}
\hline Beam ID*1 & $\begin{array}{c}\kappa^{t} \\
(\mathrm{MPa})\end{array}$ & $\begin{array}{c}\text { Normalized } \\
\boldsymbol{\kappa}^{t}\end{array}$ & $\begin{array}{l}P u \\
(k N)\end{array}$ & $\begin{array}{l}\text { Gain in } \\
\mathrm{Pu}(\%)\end{array}$ & $\begin{array}{l}P_{T h} \\
(k N)\end{array}$ & $\left(\frac{P_{U}}{P_{T}}\right)$ & $\begin{array}{c}\text { Mode of failure } \\
\text { at } \mathrm{Pu}^{* 2}\end{array}$ \\
\hline R12 & - & - & 69.14 & - & 67 & 1.03 & $\mathrm{SY}+\mathrm{CC}$ \\
\hline R16 & - & - & 110.32 & - & 109 & 1.01 & $\mathrm{SY}+\mathrm{CC}$ \\
\hline CR-R12-L1 & 1422 & $\boldsymbol{\kappa}$ & 85.15 & 23.16 & 78 & 1.09 & $\mathrm{FS}+\mathrm{FC}$ \\
\hline CR-R12-L2 & 2845 & $2 \boldsymbol{\kappa}$ & 89.12 & 28.90 & 91 & 0.98 & $\mathrm{FS}+\mathrm{FC}$ \\
\hline CR- R12-L3 & 4267 & $3 \kappa$ & 122.71 & 77.48 & 104 & 1.18 & $\mathrm{FS}+\mathrm{D}$ \\
\hline CR- R16-L1 & 1422 & $\boldsymbol{\kappa}$ & 126.17 & 14.37 & 125 & 1.01 & $\mathrm{FS}+\mathrm{D}$ \\
\hline CR- R16-L2 & 2845 & $2 \boldsymbol{\kappa}$ & 142.29 & 28.98 & 137 & 1.04 & $\mathrm{FS}+\mathrm{D}$ \\
\hline CR-R16-L3 & 4627 & $3 \boldsymbol{k}$ & 161.93 & 46.78 & 150 & 1.08 & $\mathrm{FS}+\mathrm{D}$ \\
\hline PB- R12-L1 & 605 & $0.42 \kappa$ & 84.68 & 22.48 & 72 & 1.18 & $\mathrm{FRCM}(\mathrm{C}+\mathrm{D})$ \\
\hline PB- R12-L2 & 1210 & $0.85 \kappa$ & 88.15 & 27.49 & 79 & 1.11 & $\mathrm{FRCM}(\mathrm{C}+\mathrm{D})$ \\
\hline PB- R16-L1 & 605 & $0.42 \kappa$ & 118.92 & 7.80 & 113 & 1.05 & $\mathrm{FRCM}(\mathrm{C}+\mathrm{D})$ \\
\hline PB- R16-L2 & 1210 & $0.85 \kappa$ & 123.86 & 12.27 & 119 & 1.04 & $\mathrm{FRCM}(\mathrm{C}+\mathrm{D})$ \\
\hline
\end{tabular}

${ }^{*}$ CR represents Carbon-FRCM, PB represents PBO-FRCM; $R 12$ is for 2-D12, and $R 16$ is for 2-D16 main reinforcement; L1 is for 1 layer, L2 for 2 layers, and L3 is for 3 layers of textile

${ }^{*}$ SY- steel yielding, CC-concrete crushing, FS-fabric slippage, FC-flexural cracks, D - FRCM delamination, FRCM $(C+D)$ - Cracking plane within FRCM and FRCM delamination

\subsection{Carbon Textile Reinforced Beams}

Figure 3-a shows mid-span deflection plot against the load for repaired beams with D12 as flexural steel reinforcement. Significant gain in load carrying capacity was observed for the carbon FRCM system with gains in $P_{u}$ of $23 \%$ for CR-R12-L1, 29\% for CR-R12-L2, and 77\% for CR-R12-L3. Similarly, for D16 main steel reinforcement, the load-deflection plots are shown in Figure 3-b. The associated gains in maximum load for the specimens were $14 \%$ for CR-R16-L1, 29\% for CR-R16-L2, and $47 \%$ for CR-R16-L3.
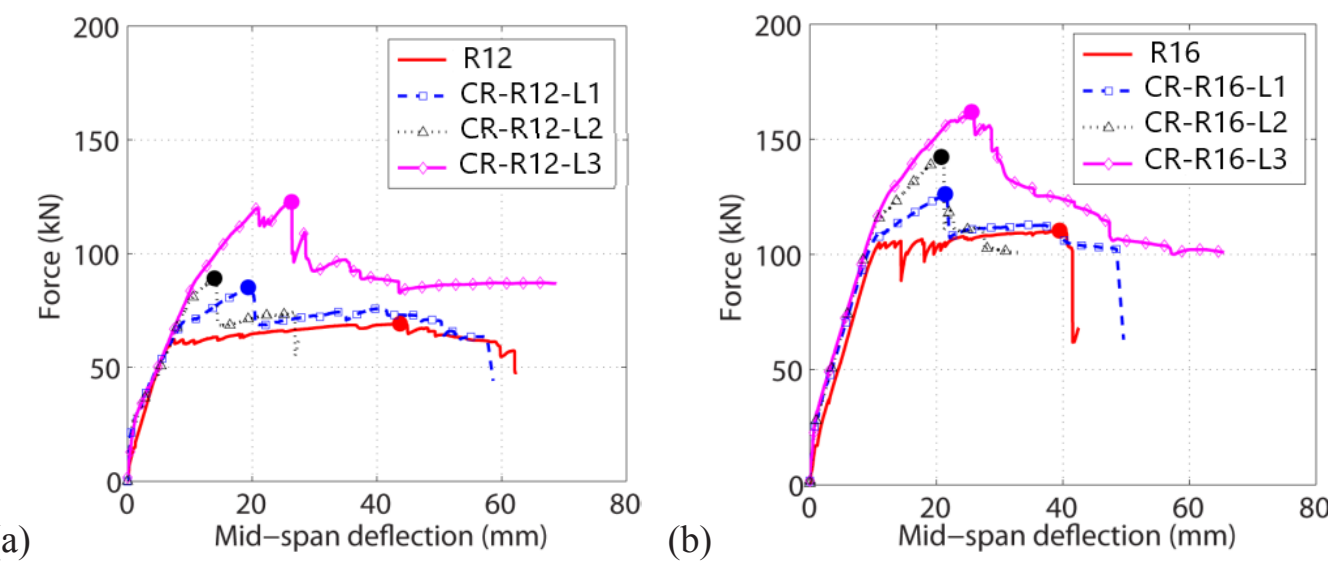

Figure 3: Load-deflection graphs for Carbon FRCM repaired specimens: (a) D12 specimens, (b) D16 specimens 


\subsection{PBO Textile Reinforced Beams}

The mid span deflection plots for PBO repaired FRCM system having D12 and D16 as main longitudinal reinforcement are shown in Figure 4-a and 4-b, respectively. The observed gains in $\mathrm{Pu}$ (expressed as Specimen - Pu increase) were (PB-R12-L1 - 22\%, PB-R12-L2 - 27\%) and (PB-R16-L1 - 8\%, PB-R16-L2 - 12\%). This also showed a considerable increase in maximum capacity compared to the unstrengthened specimens R-12 and R-16.
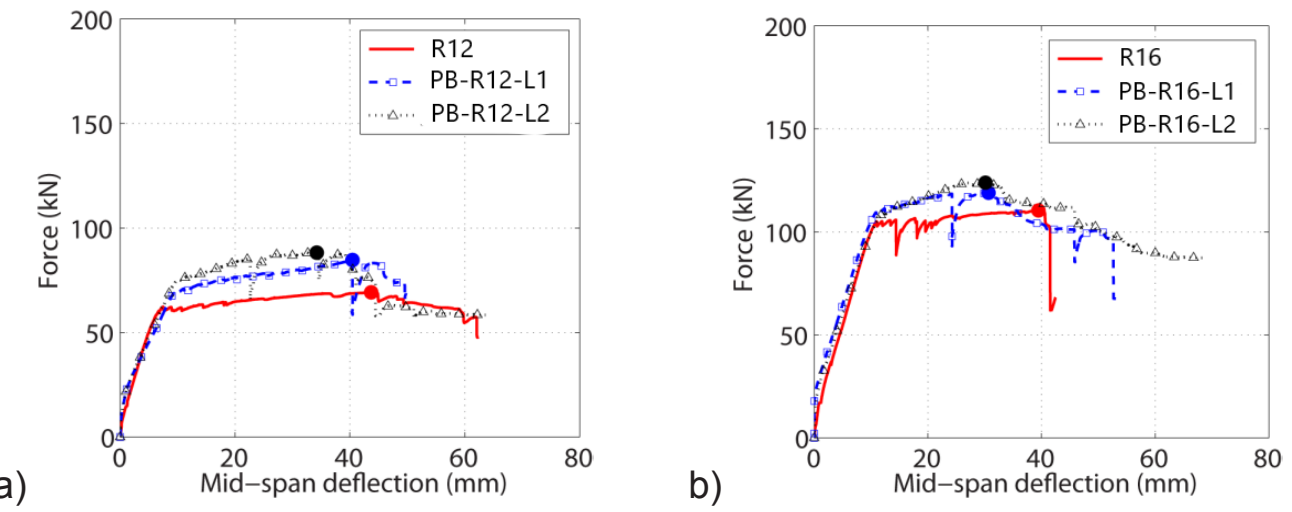

Figure 4: Load-deflection graphs for PBO FRCM repaired specimens: (a) D12 specimens, (b) D16 specimens

\section{THEORETICAL FORMULATION}

The experimental results for flexural repaired beam specimens are compared with the analytical approach to verify the ACI 549-4R-16 code (Afzal, 2016). The profiles for the stresses and the associated strains for a repaired RC are shown in Figure 5. Here, $T_{s}$ is the tension force provided by the steel reinforcement; $T_{f}$ is the tensile force provide by the FRCM reinforcement; $\mathrm{C}$ is the compressive total internal force provided by the concrete; $A_{s}$ is the area of tensile steel reinforcement; and $A_{s}$ " is the area of compression steel reinforcement.

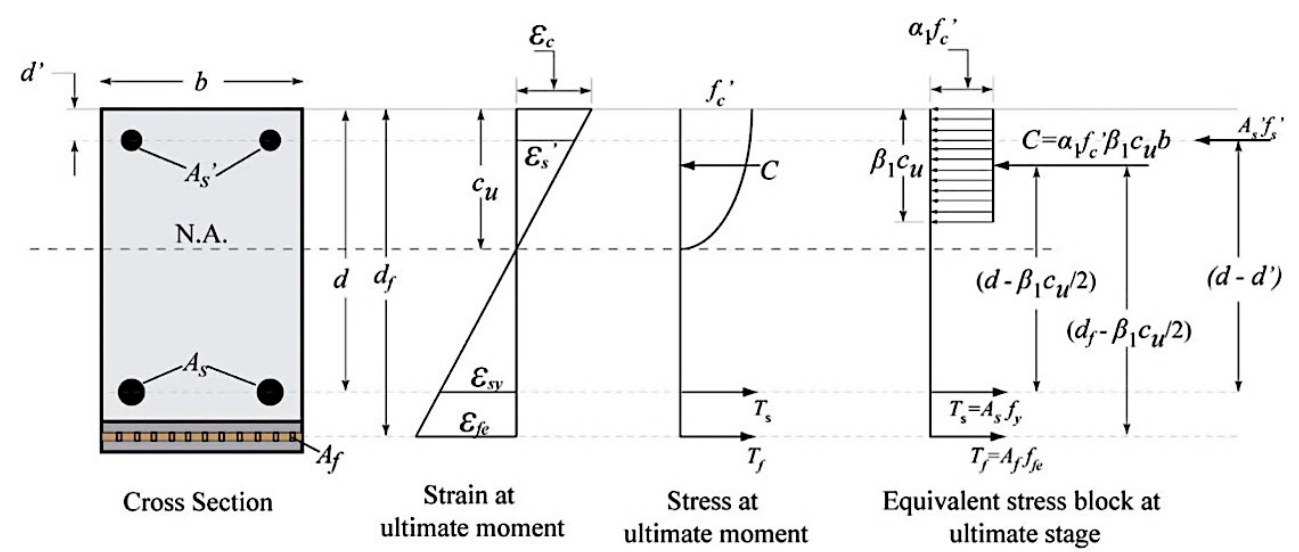

Figure 5: Internal stress and strain profile for a beam section repaired with FRCM under flexure at ultimate limit state 
Figure 6 presents a flow chart prepared according to the ACI - 549 code that was used to compute the theoretical load values for all the experimentally tested specimens, which are listed in Column 6 of Table 3. Column 7 of Table 3 shows the experimentalto-theoretical ratios for load-carrying capacity $\left(\frac{\boldsymbol{P}_{\boldsymbol{U}}}{\boldsymbol{P}_{T}}\right)$, which were close to 1.00 , indicating satisfactory computational results.

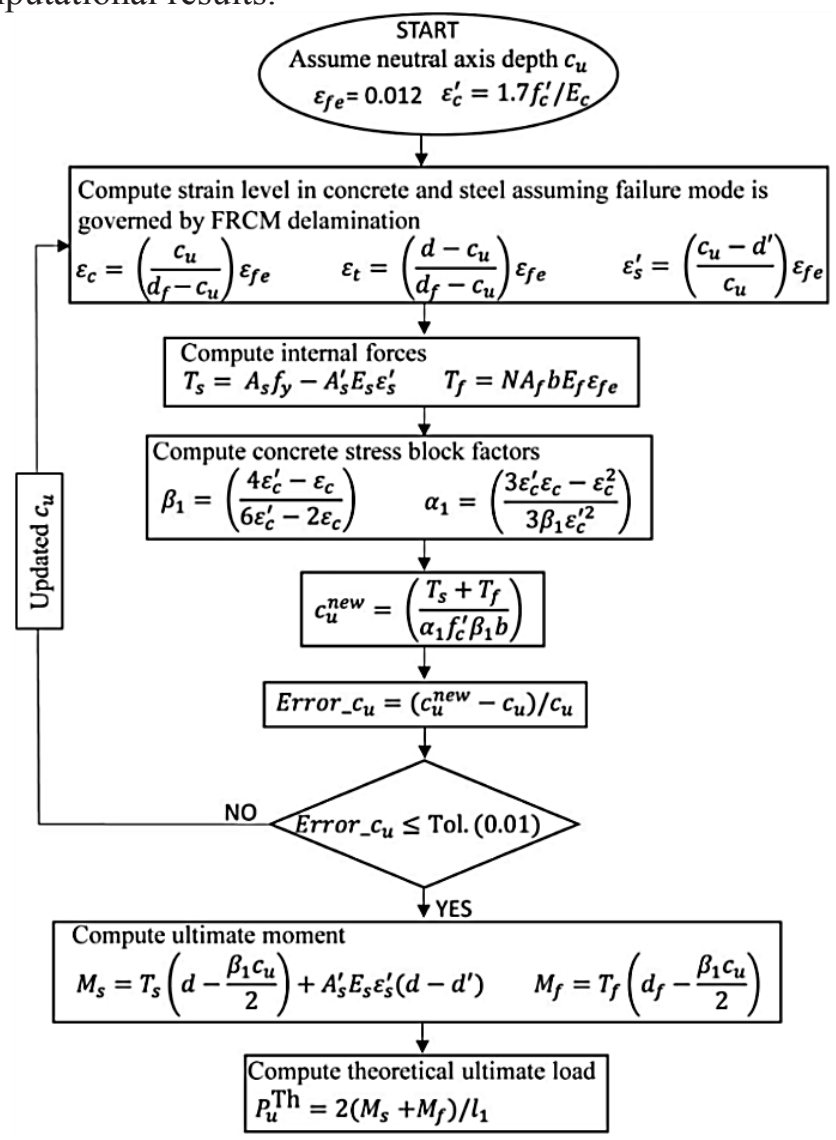

Figure 6: Flowchart for calculating the theoretical load-carrying capacity (Ebead et al., 2016)

\section{CONCLUSION}

An analytical approach to validate the ACI 549 code on experimentally tested beam specimens repaired in flexure with FRCM is presented in this study. The experimentally tested beam specimens had two different main steel reinforcement ratios and repaired with two different FRCM systems (carbon and PBO). The effect of the number of textile layers were also investigated. The following general conclusions can be drawn from the reported experimental and analytical approaches:

- The experimental results revealed that a reasonable gain in flexural strength was achieved for both FRCM systems, with up to 78\% increase in flexural capacity for carbon FRCM system and up to $27.5 \%$ for PBO FRCM system over that of their control specimens. 
- Theoretical formulation to validate the ACI-549 code for these experimentally tested beam specimens showed satisfactory computational results: the values obtained for experimental to theoretical ratio $\left(\frac{P_{U}}{P_{T}}\right)$ were quite close to 1.00 .

- The equivalent stiffness factor $\boldsymbol{\kappa}^{t}$ used in the theoretical formulation is an important factor which directly influences the maximum capacity of the repaired beams. The two FRCM systems, with similar equivalent stiffness values, showed approximately similar increase in $\mathrm{Pu}$ values.

\section{ACKNOWLEDGMENT}

This paper was made possible by NPRP grant \# NPRP 7-1720-2-641 from the Qatar National Research Fund (a member of Qatar Foundation). The findings achieved herein are solely the responsibility of the authors.

\section{REFERENCES}

ACI (American Concrete Institute) (2016). Guide to design and construction of externally bonded fabric-reinforced cementitious matrix (FRCM) systems for repair and strengthening concrete and masonry structures. (ACI 549). Farmington Hills, MI.

Abdel Baky, H. M., Ebead U. A. \& Neale, K. W. (2007). Flexural and interfacial behavior of FRP-repaired reinforced concrete beams. ASCE Journal of Composites for Construction, 11: 629-39.

Afzal, M. S. (2016). Strengthening of reinforced concrete beams With Textile-Reinforced mortars (Master dissertation).

Aidoo, J., Harries, K. A. \& Petrou, M. F. (2006). Full-scale experimental investigation of repair of reinforced concrete interstate bridge using CFRP materials. ASCE Journal of Bridge Engineering, 11: 350-58.

Almassri, B., Kreit, A., Mahmoud F. A. \& François, R. (2014). Mechanical behavior of corroded RC beams repaired by NSM CFRP rods. Composites Part B: Engineering, 64: 97-107.

Arboleda, D., Carozzi, F. G., Nanni, A. \& Poggi, C. (2015). Testing procedures for the uniaxial tensile characterization of fabric-reinforced cementitious matrix composites. ASCE Journal of Composites for Construction: 04015063.

Babaeidarabad, S., Loreto, G. \& Nanni, A. (2014). Flexural strengthening of RC beams with an externally bonded fabric-reinforced cementitious matrix. ASCE Journal of Composites for Construction, 18: 04014009.

Barros, J. A. O. \& Fortes, A. S. (2005). Flexural strengthening of concrete beams with CFRP laminates bonded into slits. Cement and Concrete Composites, 27: 471-80.

Ebead, U., Shrestha, K. C., Afzal, M .S., El Refai, A. \& Nanni, A. (2016). Effectiveness of fabric-reinforced cementitious matrix in strengthening reinforced concrete beams. Journal of Composites for Construction, 21(2), p.04016084:1-14.

Ebead, U. A. (2011). Hybrid externally bonded/mechanically fastened fiber-reinforced polymer for RC beam strengthening. ACI Structural Journal, 108: 1-10.

Ebead, U. A. \& Saeed, H. (2014). Flexural and interfacial behavior of externally bonded/ mechanically fastened fiber-reinforced polymer repaired reinforced concrete beams. $A C I$ Structural Journal, 111: 741-51. 
Ebead, U. A. \& Saeed, H. (2013). Hybrid shear strengthening system for reinforced concrete beams: An experimental study. Engineering Structures, 49: 421-33.

Elsayed, W. E., Ebead, U. A \& Neale, K. W. (2009). Studies on mechanically fastened fiberreinforced polymer strengthening systems. ACI Structural Journal, 106: 49-59.

Elsayed, W. E., Ebead, U. A. \& Neale, K. W. (2007). Interfacial behavior and debonding failures in FRP-repaired concrete slabs. ASCE Journal of Composites for Construction, 11: 619-28.

ICC (International Code Council) (2013). Acceptance criteria for masonry and concrete strengthening using fabric-reinforced cementitious matrix (FRCM) composite systems. AC434, Washington, D.C.

Kotynia, R., Abdel Baky, H. M., Neale, K. W. \& Ebead, U. A. (2008). Flexural strengthening of RC beams with externally bonded CFRP systems: Test results and 3D nonlinear FE Analysis. ASCE Journal of Composites for Construction, 12: 190-201.

Kreit, A., Al-Mahmoud, F., Castel, A. \& François, R. (2010). Repairing corroded RC beam with near-surface mounted CFRP rods. Materials and Structures, 44: 1205-17.

Loreto, G., Babaeidarabad, S., Leardini, L. \& Nanni, A. (2015). RC beams shear-repaired with fabric-reinforced-cementitious-matrix (FRCM) composite. International Journal of Advanced Structural Engineering (IJASE), 7: 341-52.

Neale, K. W., Ebead, U. A., Abdel Baky, H. M., Elsayed, W. E. \& Godat, A. (2006). Analysis of the load-deformation behavior and debonding for FRP-repaired concrete structures. Advances in Structural Engineering, 9: 751-63.

Ombres, L. (2015). Structural performances of reinforced concrete beams repaired in shear with a cement based fiber composite material. Composite Structures, 122: 316-29.

Ombres, L. (2011) Flexural analysis of reinforced concrete beams repaired with a cement based high strength composite material. Composite Structures, 94: 143-55.

Ruredil (2016) Technical datasheet, Ruredil X mesh gold data sheet. Retrieved from

(http://english.ruredil.it/SchedeProdottoENG/RuredilXMeshGOLD_ing_1.pdf) (Jul. 16, 2016).

S\&P (2016). Technical datasheet, S\&P ARMO-mesh technical data sheet. Retrieved from

(http://www.spreinforcement.ch/sites/default/files/field_product_col_doc_file/tds_sp_armomesh_ver08_2015.pdf) (Jul. 16, 2016).

Teng, J. G., De Lorenzis, L., Bo, W., Rong Li, Wong, T. N. \& Lik, L. (2006). Debonding failures of RC beams repaired with near surface mounted CFRP strips. ASCE Journal of Composites for Construction, 10: 92-105.

Tetta, Z. C., Koutas, L. N. \& Bournas, D. A. (2015). Textile-reinforced mortar (TRM) versus Fiber-Reinforced Polymers (FRP) in shear strengthening of concrete beams. Composites Part B: Engineering, 77: 338-48.

Triantafillou, T. C. \& Papanicolaou, C. G. (2006). Shear strengthening of reinforced concrete members with Textile-Reinforced Mortar (TRM) jackets. Materials and Structures, 39: 93103. 